\title{
Education improves general practitioner (GP) management of familial breast/ovarian cancer: findings from a cluster randomised controlled trial
}

\author{
E Watson*, A Clements*, A Lucassen, P Yudkin, J Mackay, J Austoker
}

J Med Genet 2002;39:779-781

$\mathrm{T}$ here has been a substantial increase in referrals from primary to secondary care of people with a family history of breast and/or ovarian cancer. The Harper report on Genetics and Cancer Services ${ }^{1}$ recommended that subjects at low risk of developing an inherited form of breast and/or ovarian cancer (that is, similar to or only slightly higher than the population risk) should receive reassurance and advice in primary care. However, referrals from primary care are often of subjects at low risk, possibly because of GPs' reported lack of knowledge and confidence in this area. ${ }^{2}$ To address this need we developed an information pack and accompanying in practice educational session, aiming at improving GP management of familial breast and/or ovarian cancer. We then conducted a cluster randomised controlled trial to evaluate these educational interventions. We hypothesised that GPs exposed to both the educational session and the information pack would make more appropriate referrals than those GPs who were mailed the pack, who in turn would do better than GPs who received neither intervention. The findings of the first phase of the evaluation, which assessed GPs' ability to assess risk using family history vignettes, have been reported elsewhere. ${ }^{3}$ This report presents the findings of a referral audit conducted in the 22 months after intervention. ${ }^{1}$

\section{METHODS}

\section{Educational interventions}

Information pack

The information pack consisted of a summary card with referral guidelines (see Appendix) and a management summary, a more detailed booklet with background facts on breast and ovarian cancer, information on assessing risk, making referral decisions, current management options, and other risk factors for breast cancer, and two patient leaflets, one on breast awareness and one specifically on breast cancer in the family. The information in the pack was guided by previous research

*These two authors contributed equally to this work. with $\mathrm{GPs}^{3}{ }^{4}$ and patients, ${ }^{5}$ as well as input from a multidisciplinary expert panel. (The full text of the information pack, Familial Breast and Ovarian Cancer - an information pack for primary care, is available on the following website: www.dphpc.ox.ac.uk/crcpcerg or from the authors.)

\section{Educational session}

The educational sessions were led by one of two researchers experienced in the field of cancer genetics and teaching (AC and EW). The session was structured around a series of overheads covering the information in the pack. The session lasted approximately one hour and interaction was encouraged.

\section{Study design}

All 170 GP practices in two counties in England (Northamptonshire and Oxfordshire), comprising 688 GPs, were randomised to one of three groups. Group A were offered an in practice educational session and each GP was given the information pack at this session (packs were mailed to GPs unable to attend the session); individual GPs in group B were sent the information pack and GPs in group $\mathrm{C}$ were neither offered the session nor sent the pack. Between March 1999 and December 2000, all GP referral letters concerning a family history of breast and/or ovarian cancer sent post-intervention to the relevant genetics centres and breast clinics were audited to determine the proportion of referrals that met the local guidelines. These letters were classified as "appropriate" (that is, meeting guideline criteria in the Appendix) or "inappropriate" (that is, not meeting guideline criteria in the Appendix, or containing insufficient information regarding number and ages of affected relatives to determine if guideline criteria were met).

\section{RESULTS}

A total of 236 post-intervention referrals were received from GPs in the trial; 27 referrals were excluded as they contained an additional valid reason for referral despite not meeting the guideline criteria, for example, recommendation for referral

\begin{tabular}{llll} 
Table 1 Appropriate and inappropriate referrals, by intervention & group. Values are percentages (number) \\
\hline & $\begin{array}{l}\text { Group A (session and } \\
\text { pack) } n=56\end{array}$ & $\begin{array}{l}\text { Group B (pack only) } \\
n=48\end{array}$ & $\begin{array}{c}\text { Group C } \\
\text { (control) } n=57\end{array}$ \\
\hline $\begin{array}{l}\text { Appropriate } \\
\quad \text { Met referral criteria }\end{array}$ & $75.0(42)$ & $68.7(33)$ & $52.6(30)$ \\
$\begin{array}{l}\text { Inappropriate } \\
\text { Did not meet referral criteria } \\
\text { Insufficient information to determine if guideline criteria met }\end{array}$ & $12.5(7)$ & $14.6(7)$ & $19.3(11)$ \\
\hline
\end{tabular}

Chi-squared test for trend (appropriate $v$ inappropriate) after adjustment for clustering within practices, $p=0.016$. 
from another specialist. Where a GP sent more than one referral letter only the first was included, leaving 161 referral letters remaining for analysis (from 97 practices).

The results are presented in table 1 . There was a significant trend in the proportion of appropriate referrals made, with GPs who received both the educational session and the information pack making the highest proportion of appropriate referrals $(75.0 \%)$ and GPs who received neither intervention making the lowest $(52.6 \%)$. Twenty-eight percent of referral letters made by the GPs in the control group who received neither intervention contained insufficient information to determine if the guideline criteria were met, compared to only $12.5 \%$ of GPs in the group exposed to both interventions.

\section{DISCUSSION}

Reviews of published reports have tended to conclude that the provision of printed materials alone are of limited usefulness in changing clinical practice ${ }^{6}$ and that referral guidelines are more likely to be effective if disseminated through educational initiatives. ${ }^{7}$ However, few published studies have rigorously evaluated the impact of referral guidelines. We have shown that mailing GPs an information pack containing referral guidelines results in a higher proportion of GPs making appropriate referrals and fewer inadequate letters, and that this improvement is increased further when the pack is combined with a practice educational session. Providing referral guidelines and education on a topic which is relatively new to primary care, and involving GPs in the development of the pack, are likely to have been factors in achieving these improvements.

Wider circulation of this information pack may result in more appropriate GP referrals, with benefits for the person, the GP, and the genetics service. One of the possible negative consequences of referring a subject at low risk is the unnecessary anxiety caused to that person. Anxiety may result from the implication that their family history is of such significance that it warrants a referral to a genetics specialist, and also from the possible waiting period for an appointment before reassurance could be given. GPs who receive the information pack will benefit from increased confidence in conducting effective consultations in this area. Reducing the number of low risk referrals and inadequate letters will also optimise the time specialists have to focus on families at higher risk. Genetic centres with the resources to provide intensive GP education can expect to see further improvements in the quality of referrals, and also to increase GPs' understanding and confidence in this area. ${ }^{3}$ Further studies are needed to understand why some GPs who have received intensive education are still making low risk referrals.

\section{Further information}

Following the completion of this study, the information pack has been endorsed by the Cancer Genetics Group of the British Society of Human Genetics and has been circulated to genetics departments for distribution to primary care. For further information or additional copies of the pack please contact the Cancer Research UK Primary Care Education Research Group (01865 226 788).

\section{APPENDIX}

\section{Family history of breast and/or ovarian cancer: referral} guidelines

If a patient's family history fits within any of those listed below then this may indicate a higher risk of developing an inherited form of breast and/or ovarian cancer and the patient may benefit from referral for more detailed assessment. If you are unsure about whether or not to refer a person please contact the genetics service for advice.

It is important to remember that these are simply guidelines and that some of the patients who fit the referral criteria will be considered low risk following assessment.

\section{Breast cancer}

- Three close relatives from the same side of the family diagnosed at any age.

- Two close relatives from the same side of the family with an average age of diagnosis under 60 years.

- Mother or sister diagnosed under 40 years.

- Father or brother with breast cancer diagnosed under 60 years.

- One close relative with bilateral breast cancer, with the first cancer diagnosed under 50 years.

\section{Breast and ovarian cancer}

- One close relative diagnosed with ovarian cancer at any age and at least two close relatives with breast cancer with an average age of diagnosis under 60 years, all from the same side of the family.

- One close relative diagnosed with ovarian cancer at any age and at least one close relative diagnosed with breast cancer under 50 years from the same side of the family.

- One close relative diagnosed with breast cancer under 50 years and ovarian cancer at any age.

\section{Ovarian cancer}

- Two close relatives from the same side of the family, at least one of whom is either a mother or sister, diagnosed at any age with ovarian cancer.

A close relative means a parent, brother, sister, child, grandparent, aunt, uncle, nephew, or niece.

\section{Please note}

- Inherited forms of breast and ovarian cancer can be passed down through the father's side of the family.

- Subjects of Ashkenazi Jewish origin are at higher risk, and family histories which do not meet the guidelines may still warrant referral; please contact your local genetics service for further advice.

\section{ACKNOWLEDGEMENTS}

This study was funded by the Cancer Research Campaign. We would like to thank the following people for their assistance with the setting up and running of the study: Mr Bob Stewart, Dr Jenny Wise, and Trudi Vanni (Breast Unit, Kettering General Hospital); Dr Sue Price (Department of Clinical Genetics, Northampton General Hospital); Mr Mark Orr and Mr Carl Griffiths (Breast Unit, Horton Hospital, Banbury); Dr Sarah Greening and Dr Paul Barclay of Northampton GP Post-graduate Education Centre and Dr John Humphreys and Dr Judy Shakespeare of Oxford Post-graduate Education Centre; Mrs Jean Harcourt (ICRF GP Research Group, Oxford).

\section{Authors' affiliations}

E Watson, A Clements, J Austoker, Cancer Research UK Primary Care Education Research Group, Department of Primary Health Care,

University of Oxford, Institute of Health Sciences, Oxford OX3 7LF, UK A Lucassen* Department of Clinical Genetics, Churchill Hospital, Oxford, UK

P Yudkin, Department of Primary Health Care, University of Oxford, Institute of Health Sciences, Oxford OX3 7LF, UK

J Mackay, North East Thames Clinical Genetics Service, Great Ormond St Hospital, London, UK

Correspondence to: Dr E Watson, Cancer Research UK Primary Care Education Research Group, Department of Primary Health Care, University of Oxford, Institute of Health Sciences, Oxford OX3 7LF, UK. crcpcerg@dphpc.ox.ac.uk

*Present address: Wessex Regional Genetics Service, Princess Anne Hospital, Southampton, UK.

\section{REFERENCES}

1 Working Group for the Chief Medical Officer. Genetics and cancer services. Report of a Working Group for the Chief Medical Officer, Department of Health. London: Department of Health, 1998.

2 Watson E, Shickle D, Qureshi N, Emery J, Austoker J. The 'new genetics' and primary care: GPs' views on their role and their educational needs. Family Pract 1999;16:420-5.

3 Watson E, Clements A, Yudkin P, Rose P, Buckach C, Mackay J, Lucassen A, Austoker J. Evaluation of the impact of two educational interventions on GP management of familial breast/ovarian cancer cases: a cluster randomised controlled trial. Br J Gen Pract 2001;51:817-22.

4 Watson E, Austoker J, Lucassen A. A study of GP referrals to a family cancer clinic for breast/ovarian cancer. Fam Pract 2001;18:131-4. 
5 Andermann A, Watson E, Lucassen A, Austoker J. The primary care consultation needs of women with a family history of breast cancer. Comm Genetics (in press)

6 Grol R. Implementing guidelines in general practice care. Qual Health Care 1992;2:184-91.
7 Russell IT, Grimshaw JM. The effectiveness of referral guidelines: a review of the methods and findings of published evaluations. In Roland M, Coulter A, eds. Hospital referrals. Oxford: Oxford University Press, 1992:179-211.

\section{Want full access but don't have a subscription?}

\section{Pay per access}

For just US $\$ 25$ you can have instant access to the whole website for 30 days. During this time you will be able to access the full text for all issues (including supplements) available. You will also be able to download and print any relevant pdf files for personal use, and take advantage of all the special features Journal of Medical Genetics online has to offer.

\section{www.jmedgenet.com}

